\title{
Comparision of Brucella and Non-Brucella Epididymo-orchitis
}

\author{
Nesibe Korkmaz ${ }^{1,2}$, Mahmut Taha Ölçücü ${ }^{3,4}$ and Ferhat Ateş ${ }^{5}$ \\ ${ }^{1}$ Department of Infectious and Clinical Microbiology Diseases, Agri State Hospital, Agri, Turkey \\ ${ }^{2}$ Department of Infectious and Clinical Microbiology Diseases, Ankara Kahramazan Kazan State Hospital, Kahramankazan, Ankara, Turkey \\ ${ }^{3}$ Department of Urology, Agri State Hospital, Agri, Turkey \\ ${ }^{4}$ Department of Urology, Antalya Training and Research Hospital, University of Health Sciences, Antalya, Turkey \\ ${ }^{5}$ Department of Urology, University of Health Sciences, Sultan Abdülhamid Han Training and Research Hospital, Istanbul, Turkey
}

\begin{abstract}
Objective: To find parameters for differential diagnosis between Brucella epididymo-orchitis (BEO) and non-brucella epididymo-orchitis (NBEO) cases with comparison of BEO and NBEO in terms of inflammatory markers, full urinalysis (FU) for pyuria, and abscess formation (AF).

Study Design: Descriptive study.

Place and Duration of Study: Agri State Hospital Urology and Infectious Disease Clinics, between January 2014 and November 2017.

Methodology: Data of the patients, who were diagnosed with epididymo-orchitis, were divided in BEO and NBEO groups on the basic of serum agglutination test. Parameters including age, white blood cell neutrophil, lymphocyte, monocyte, platelet, mean platelet volume, C-reactive protein (CRP), neutrophil/lymphocyte ratio, monocyte/lymphocyte ratio, platelet / lymphocyte ratio, and FU. The values were statistically compared.

Results: One hundred and thirty-eight (138) patients were found eligible for the study. Twenty-three (23) of these patients (16.66\%) had BEO, and 115 (83.33\%) had NBEO. BEO vs. NBEO cases were significantly different regarding mean age (26.17 \pm 8.15 vs. $48.53 \pm 21.78$ years, $p=0.0001)$ and frequency of pyuria $(3,13.04 \%)$ vs. $89(77.39 \%, p=0.001)$. However CRP values i.e. 6.07 \pm 6.59 vs. $6.07 \pm 5.85 \mathrm{mg} / \mathrm{dl}(\mathrm{p}=0.999)$ was not significantly different.

Conclusion: BEO cases are often younger and do not have pyuria or abscess formation. High frequency of pyuria was found in NBEO cases. CRP levels cannot be used in the differential diagnosis between BEO and NBEO cases.
\end{abstract}

Key Words: Abscess formation, Brucella epididymo-orchitis, C-reactive protein, Orchiectomy, Pyuria.

How to cite this article: Korkmaz N, Ölçücü MT, Ateş F. Comparision of Brucella and Non-Brucella Epididymo-orchitis. J Coll Physicians Surg Pak 2020; 30(04):403-406. DOI: https://doi.org/10.29271/jcpsp.2020.04.403.

\section{INTRODUCTION}

Brucellosis is a zoonotic infectious disease caused by bacterial genus Brucella, which can involve various organs and systems. ${ }^{1}$ Drinking or eating non-pasteurised dairy products can cause brucellosis. Brucellosis can involve the musculoskeletal system, gastrointestinal system, genitourinary system and central nervous system. In genitourinary system, complications include epididymo-orchitis, prostatitis, testicular abscess, seminal vesiculitis, pyelonephritis, cystitis and renal abscesses. ${ }^{2}$ The most common genitourinary complication of brucellosis is epididymoorchitis, which constitutes 2 to $20.6 \%$ of the overall brucellosis cases. $^{3}$

Correspondence to: Dr. Mahmut Taha, Department of Urology, University of Health Sciences, Antalya Training and Research Hospital, 07100 Muratpaşa, Antalya, Turkey E-mail: matah_ol@hotmail.com

Received: October 30, 2019; Revised: October 30, 2019;

Accepted: November 17, 2019

DOI: https://doi.org/10.29271/jcpsp.2020.04.403
In case of Brucella epididymo-orchitis (BEO), non-specific systemic symptoms can be seen, such as pain, redness, swelling in the testicle accompanied by sweating, high fever, weakness, lymphadenopathy and hepatosplenomegaly. ${ }^{4}$

Since there are no non-culture methods to differentiate between the two conditions, there is a need to establish relevant parameters. This study was conducted to find parameters for differential diagnosis between BEO and non-brucella epididymo-orchitis (NBEO) cases with comparison in terms of inflammatory markers, full urinalysis (FU) for pyuria and abscess formation (AF).

\section{METHODOLOGY}

After approval from Erzurum Ataturk University, Faculty of Medicine, Ethics Committee of Clinical Researches (Approval No. B.30.2.ATA.0.01.00/12), data of all patients diagnosed with epididymo-orchitis between January 2014 and November 2017 in Agri State Hospital Urology or Infectious Diseases and Clinical Microbiology Clinics were examined. Patients with diabetes mellitus, immunosuppression status, malignancy, haematological problems were excluded. Diagnosis of epididymo-orchitis was made on the basis of pain, swelling, redness, high temperature in the testicles, high white blood cell (WBC), high CRP, pyuria and 
epididymo-orchitis findings on scrotal ultrasound. As for distinguishing between BEO and NBEO, those having serum agglutination test (SAT) titer of $\geq 1: 160$ were considered as $B E O$, and the rest were considered as NBEO.

Table I. Comparison of brucella and non-brucella epididymo-orchitis cases.

\begin{tabular}{|l|c|c|c|}
\hline & $\begin{array}{c}\text { Brucella } \\
\text { Epididymo- } \\
\text { Orchitis } \\
\text { (n=23, 16.66\%) } \\
\text { (mean } \pm \text { SD) }\end{array}$ & $\begin{array}{c}\text { Non-brucella } \\
\text { epididymo-orchitis } \\
\text { (n=115, 83.33\%) } \\
\text { (mean } \pm \text { SD) }\end{array}$ & p \\
\hline Age (year) & $26.17 \pm 8.15$ & $48.53 \pm 21.78$ & 0.0001 \\
\hline White blood cell $(\mu \mathrm{l})$ & $11252 \pm 3483$ & $11634 \pm 4114$ & 0.678 \\
\hline Neutrophil $(\mu \mathrm{l})$ & $7669 \pm 2864$ & $7779 \pm 3274$ & 0,881 \\
\hline Lymphocyte $(\mu \mathrm{l})$ & $2050 \pm 834$ & $2525 \pm 1279$ & 0.091 \\
\hline Monocyte $(\mu \mathrm{l})$ & $1048 \pm 844$ & $1104 \pm 924$ & 0.789 \\
\hline Platelet $(\mu \mathrm{l})$ & $234869 \pm 69858$ & $258275 \pm 84523$ & 0.215 \\
\hline Mean platelet volume (fL) & $8.38 \pm 1.31$ & $8.57 \pm 1.15$ & 0.476 \\
\hline C- Reactive protein (mg/dl) & $6.07 \pm 6.59$ & $6.07 \pm 5.85$ & 0.999 \\
\hline Neutrophile / Lymphocyte ratio & $4.95 \pm 4.33$ & $3.59 \pm 2.02$ & 0.346 \\
\hline Monocyte / Lymphocyte ratio & $0.70 \pm 0.82$ & $0.40 \pm 0.18$ & 0.283 \\
\hline Platelet / Lymphocyte ratio & $133.07 \pm 53.72$ & $122.20 \pm 58.09$ & 0.408 \\
\hline Pyuria & $3(13.04 \%)$ & $89(77.39 \%)$ & 0.001 \\
\hline Abscess formation & $0(0 \%)$ & $11(9.56 \%)$ & 0.211 \\
\hline Orchiectomy & $0(0 \%)$ & $12(10.43 \%)$ & 0.217 \\
\hline
\end{tabular}

Table II: Microorganisms isolated in urine samples and treatment approach in BEO and NBEO cases.

\begin{tabular}{|c|c|c|c|}
\hline & $\begin{array}{l}\text { Microorganism } \\
\text { isolated in } \\
\text { urine sample }\end{array}$ & Treatment & Results \\
\hline $\begin{array}{l}\text { Cases with abscess } \\
\text { Formation in } \\
\text { BEO group }(n=0)\end{array}$ & - & - & - \\
\hline $\begin{array}{l}\text { Cases without abscess } \\
\text { formation in BEO group } \\
(\mathrm{n}=23)\end{array}$ & $\begin{array}{c}\text { None : } 8 \\
\text { Unknown: } 15\end{array}$ & MT: 23 & Successful: 23 \\
\hline $\begin{array}{l}\text { Cases with abscess } \\
\text { formation } \\
\text { in NBEO group } \\
(\mathrm{n}=11)\end{array}$ & $\begin{array}{c}\text { E.coli : } 7 \\
\text { K.pneumoniae: } 1 \\
\text { None: } 2 \\
\text { Unknown: } 1\end{array}$ & $\begin{array}{c}\text { MT: } 9 \\
\text { MT+AD:2 }\end{array}$ & $\begin{array}{c}\text { Successful: } 2 \\
\text { Orchiectomy: } 9\end{array}$ \\
\hline $\begin{array}{l}\text { Cases without abscess } \\
\text { formation in NBEO } \\
\text { group } \\
(104)\end{array}$ & $\begin{array}{c}\text { E.coli : } 47 \\
\text { K.pneumoniae: } 3 \\
\text { P. aeruginosa :1 } \\
\text { None: } 32 \\
\text { Unknown: } 21\end{array}$ & MT: 104 & $\begin{array}{l}\text { Successful: } 101 \\
\text { Orchiectomy: } 3\end{array}$ \\
\hline
\end{tabular}

For the treatment of BEO, doxycycline and rifampicin antibiotics were used; For the treatment of NBEO, ciprofloxacin and ceftriaxone were used, and for resistant cases, the carbapenem group of antibiotics were used. Antibiotic treatment was also regulated according to the sensitive microorganism in urine samples. For the cases not responding to the medical treatment and whether abscess formation (AF) occured or not, abscess drainage or orchiectomy were performed.
Table III. Review of the studies which compared to brucella and non-brucella epididymo-orchitiscases.

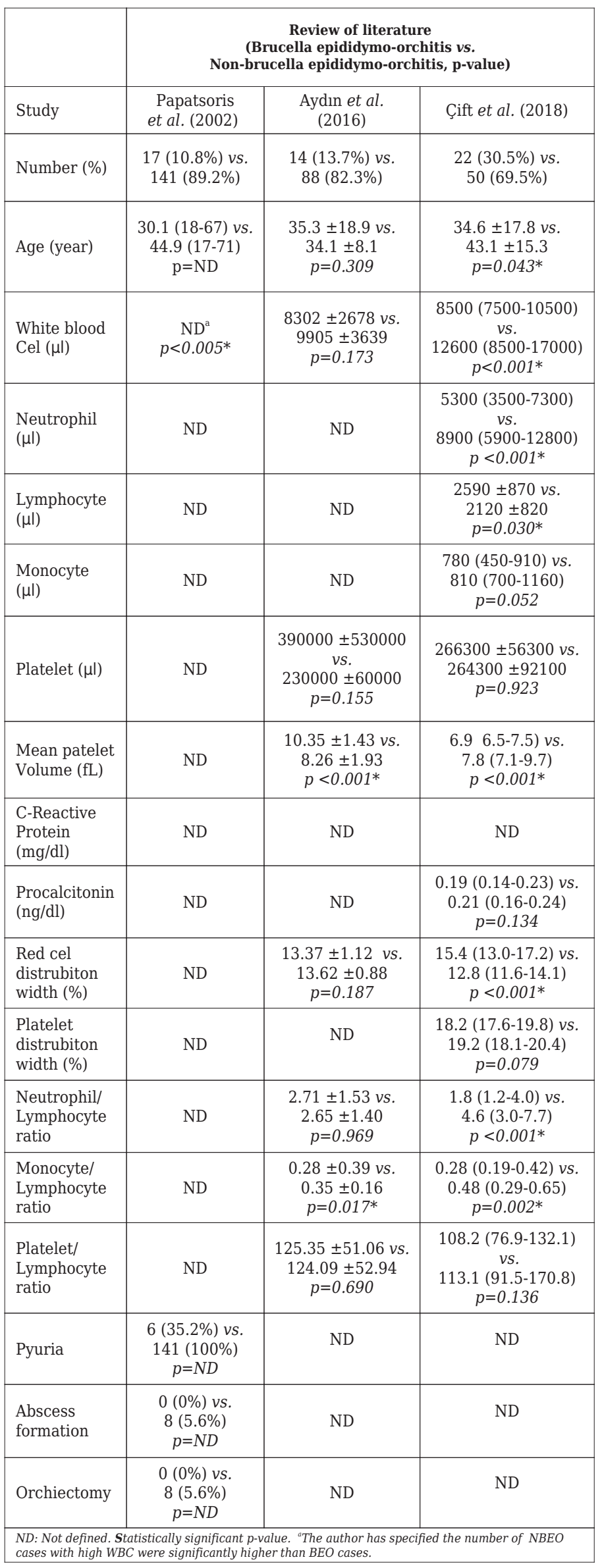


Data from BEO and NBEO patients such as age, WBC, neutrophil, lymphocyte, monocyte, platelet mean platelet volume (MPV), CRP, neutrophil/lymphocyte ratio (NLR), monocyte/lymphocyte ratio (MLR), platelet/lymphocyte ratio (PLR), FU, microorganism isolated in urine samples, AF and orchiectomy rates (OR) were recorded. The results were statistically compared. Statistical analysis was performed with Statistical Package for the Social Sciences (SPSS) 15.0. Chi-square test was used for categorical data; an independent T-test and a Mann-Whitney $U$ test were used for quantitative variables. A p-value of $<0.05$ was evaluated as statistically significant.

\section{RESULTS}

One hundred and thirty eight (138) patients were found to be eligible for the study. Twenty-three (23) of these patients (16.66\%) had BEO, and 115 (83.33\%) had NBEO. When BEO vs. NBEO were compared, statistically significant differences were found regarding mean age $(26.17 \pm 8.15$ vs. $48.53 \pm 21.78$ years, $p=0.0001$ ) and pyuria $3=13.04 \%$ vs. $89=77.39 \%, p=0.001$, Table I). There were no statistically significant differences in the other parameters (Tablel).

There were 11 cases with testicular abscess formation in NBEO group, but none in BEO group. All those having abscess formation also had pyuria and E.coli or K. pneumoniae were isolated in most of the urine samples. Two cases had undergone abscess drainage and were successfully treated. Three patients in NBEO group were treated with orchiectomy, in the presence of abscess, as they did not respond to medical treatment. There was no case who were treated with orchiectomy in BEO group. No sepsis or Fornier gangrene has developed in any case. All those results and additional data weresummarized in Tablell.

\section{DISCUSSION}

The heterogeneity, increased size in testicle and epididymis, hydrocele and increase in scrotum thickness can be seen in scrotal ultrasound (US), increase in values such as WBC, CRP, AST and ALT in BEO cases. ${ }^{1,5-8}$ However, all of these findings are non-specific. Abscess can develop, and the US appearance can even imitate testicular masses. ${ }^{9,10}$ For this reason, physicians should be careful when diagnosing an abscess. In addition to the clinical symptoms of epididymo-orchitis, BEO is diagnosed by positive SAT test. ${ }^{11} \mathrm{BEO}$ generally responds well to medical treatment. Doxycycline and rifampicin are the most common treatmentagents. ${ }^{12}$

Brucellosis is usually seen in younger population. ${ }^{13,14}$ It was reported in previous studies that BEO is often seen in younger males aged 20-42 years as in systemic brucellosis. ${ }^{4,6,15-22}$ Furthermore, among all epididymo-orchitis, the BEO is less likely to be seen as compared to NBEO (10-28\%). ${ }^{15,22,23}$ In this study, it was also found that the age average and the prevalence of those having BEO are consistent with the literature.

In the BEO studies, the parameters which are usually elevated in inflammatory conditions such as WBC, CRP and the erythrocyte sedimentation rate (ESR) are often reported as being normal. ${ }^{1,6,16,17,19,24}$ On the other hand, some studies show a significant increase in the above mentioned parameters. ${ }^{4}$ To the best of authors' knowledge, there are only three studies in the literature comparing BEO and NBEO in terms of inflammatory markers. ${ }^{15,22,23}$
In the study of Papatsoris et al., the average age in the BEO group is lower as compared to the NBEO group. ${ }^{15}$ In that study, the leucocytosis (mainly neutrophil weighted) was significantly greater in the NBEO group. In addition, as in this study, the pyuria, AF and OR in both the BEO and NBEO groups were compared, and similar results with this study were obtained (Table III). Using more biochemical data, having data clarified and including statistical methods could make this study of better quality.

In a comparison between 22 patients with $\mathrm{BEO}$ and 50 patients with NBEO in a study conducted by Çift et al., ${ }^{22}$ age, WBC, MPV, neutrophil NLR and MLR were reported as significantly lower in the BEO group. In contrast, the red cell distribution width (RDW) and lymphocyte values were found to significantly higher than the NBEO group (Table III). In our study, no difference was found between the groups in terms of procalcitonin. Another similar study conducted by Aydın et al., it was found that the MPV and MLR were significantly higher in the BEO group (Table III). ${ }^{23}$ In our study, no significant difference was found in the inflammatory markers and their ratios to each other. CRP levels were also compared, which is an acute phase reactant. CRPlevels were found as increased a bit in both groups, such as WBC. However, when the groups were compared, CRP levels were not significantly different between the groups (Table I). In terms of age prevalence, similar findings with the studies of Çift et al. and Papatsoris et al. were founded. However, there was no information provided concerning pyuria, AF and $O R$ in these studies. For this reason, these studies were not compared in terms of the mentioned parameters.

When the studies evaluating only BEO were considered, it was observed that FU was similar and generally normal. Abnormal FU (pyuria, haematuria, proteinuria or combinations thereof) may be seen. Many researchers have reported FU ratios in the studies, respectively, as $13 / 42$ (30.9\%), 7/59 (11.9\%), 2/30 (6.7\%) and 6/26 $(23 \%) .{ }^{16,17,19,21}$ Likewise, the studies reported that the AF ratios in their patients having BOE were, 6/337 (1.7\%), 2/28 (7.1\%), 2/19 (10.5\%), 5/59 (8.4\%), 0/27 (0\%), 0/26 (0\%), 2/48 (4.1\%), 1/53 (1.8\%), 5/30 (16.6\%) and 0/21 (0\%), respectively. ${ }^{1,4,6,16-21,24}$

In addition the reported OR depending on abscess were, $6 / 337$ (1.7\%), 2/28 (7.1\%), 2/19 (10.5\%), 3/59 (5\%), 0/27 (0\%), 0/26 (0\%), $0 / 48(0 \%), 1 / 53(1.8 \%), 1 / 30(3.3 \%)$ and $0 / 21(0 \%)$, respectively. The orchiectomies were performed because the suspicion of tumor wereadded to these ratios.

In the BEO cases with $A F$, did not respond to the medical treatments, it was reported that successful results were observed in the studies in which additional abscess drainage (AD) was applied in addition to the medical treatment prior to the orchiectomy. The success ratios of the abscess drainages have been as $1 / 1(\% 100)$, $2 / 2(100 \%), 2 / 3(66.6 \%)$ and $3 / 3$ (100\%), respectively. ${ }^{1,16,21,25}$ In the present study, two cases have been treated with abscess drainage with $100 \%$ success ratio.

Small sample size and retrospective design were the main limitations of this study. Prospective larger samples would be better to compare BEO and NBEO cases. Lack of comparison of the stated results after the treatments of BEO and NBEO cases were another limitation of the study. Comparison of the results after the treatments of the groups may help understand treatment response. To the best of authors' knowledge, this study is the first study comparing BEO and NBEO patients . in terms of their CRP levels. 


\section{CONCLUSION}

If the patient is young and does not have pyuria, a strong possibility of BEO than NBEO is considered. Testicular abscess drainage would be useful before taking an orchiectomy decision in the cases of developing AF. CRP levels cannot be used in the differential diagnosis between BEO and NBEO patients were considered. All of these findings need to be confirmed in prospective studies with cases having broader serials.

\section{ETHICALAPPROVAL:}

Ethics committee approval was received for this study from Erzurum Ataturk University, Faculty of Medicine, Ethics Committee of Clinical Researches (Approval No. B.30.2.ATA.0.01. $00 / 12$ ).

\section{PATIENTS' CONSENT:}

Data of this retrospective study was collected from clinical archive.

\section{CONFLICT OF INTEREST:}

Authors declared no conflict of interest.

\section{AUTHORS' CONTRIBUTION:}

NK: Conception, materials, data collection and analysis, writing, critical review.

MTÖ: Conception, materials, data collection and analysis, writing, critical review.

FA: Statistical analysis, critical review.

\section{REFERENCES:}

1. Erdem H, Elaldi N, Ak O, Gulsun S, Tekin R, Ulug M, et al. Genitourinary brucellosis: Results of a multicentric study. Clin Microbiol Infect 2014; 20:0847-53.

2. Bosilkovski M, Kamiloski V, Miskova S, Balalovski D, Kotevska V, Petrovski M. Testicular infection in brucellosis: Report of 34 cases. J Microbiol Immunol Infect 2016; 51:82-7.

3. Gul HC, Erdem H, Bek S. Overview of neurobrucellosis: A pooled analysis of 187 cases. Int J Infect Dis 2009; 13:e339-43.

4. Savasci U, Zor M, Karakas A, Aydin E, Kocaaslan R, Oren NC, et al. Brucellar epididymo-orchitis: A retrospective multicenter study of 28 cases and review of the literature. Travel Med Infect Dis 2014; 12:667-72.

5. Ozturk A, Ozturk E, Zeyrek F, Onur K, Sirmatel O, Kat N. Comparison of brucella and non-specific epididymorchitis: Gray scale and color Doppler ultrasonographic features. Eur J Radiol 2005; 56:256-62.

6. Gul HC, Akyol I, Sen B, Adayener C, Haholu A. Epididymoorchitis due to brucella melitensis: Review of 19 patients. Urol Int 2009; 82:158-61.

7. Colmenero JD, Reguera JM, Martos F, Sanchez-De-Mora D, Delgado $M$, Causse $M$, et al. Complications associated with brucella melitensis infection: A study of 530 cases. Medicine (Baltimore) 1996; 75:195-211.

8. Khan MS, Humayoon MS, Al Manee MS. Epididymo-orchitis and brucellosis. BrJ Urol 1989; 63:87-9.

9. Kocak I, Dundar M, Culhaci N, Unsal A. Relapse of brucellosis simulating testis tumor. Int J Urol 2004; 11:683-5.

10. Kaya F, Kocyigit A, Kaya C, Turkcuer I, Serinken M, Karabulut $\mathrm{N}$. Brucellar testicular abscess presenting as a testicular mass: Can color doppler sonography be used in differentiation? Eur J Radiol 2015; 15:43-6.

11. Akhvlediani T, Bautista CT, Garuchava N, Sanodze L, Kokaia $\mathrm{N}$, Malania L, et al. Epidemiological and clinical features of brucellosis in the country of georgia. PLoS One 2017; 12: e0170376.

12. Solera J, Martinez-Alfaro E, Saez L. Meta-analysis of the efficacy of the combination of rifampicin and doxycycline in the treatment of human brucellosis. Med Clin (Barc) 1994; 102:731-8.

13. Wise RI. Brucellosis in the united states past, present and future. JAMA 1980; 244:2318-22.

14. Doganay M, Aygen B. Human brucellosis: An overview. Int J Infec Dis 2003; 7:173-82.

15. Papatsoris AG, Mpadra FA, Karamouzis MV, Frangides CY. Endemic brucellar epididymo-orchitis: A 10-year experience. Int J Infect Dis 2002; 6:309-13.

16. Navarro-Martinez A, Solera J, Corredoira J, Beato JL, MartinezAlfaro E, Atienzar M, et al. Epididymoorchitis due to brucella mellitensis: A retrospective study of 59 patients. Clin Infect Dis 2001; 33:2017-22.

17. Celen MK, Ulug M, Ayaz C, Geyik MF, Hosoglu S. Brucellar epididymo-orchitis in southeastern part of Turkey: An 8 year experience. Braz J Infect Dis 2010; 14:109-15.

18. Memish ZA, Venkatesh S. Brucellar epididymo-orchitis in Saudi Arabia: A retrospective study of 26 cases and review of the literature. BJU Int 2001; 88:72-6.

19. Colmenero JD, Munoz-Roca NL, Bermudez P, Plata A, Villalobos A, Reguera JM. Clinical findings, diagnostic approach, and outcome of brucella melitensis epididymoorchitis. Diagn Microbiol Infect Dis 2007; 57:367-72.

20. Roushan MR, Baiani M, Javanian M, Kasaeian AA. Brucellar epididymo-orchitis: Review of 53 cases in babol, northern Iran. Scand J Infect Dis 2009; 41:440-4.

21. Najafi N, Ghassemian R, Davoody AR, Tayebi A. An unusual complication of a common endemic disease: Clinical and laboratory aspects of patients with brucella epididymoorchitis in the north of Iran. BMC Res Notes 2011; 4:286.

22. Cift A, Yucel MO. Comparison of inflammatory markers between brucella and non-brucella epididymo-orchitis. Int Braz J Urol 2018; 44:771-8.

23. Aydin E, Karadag MA, Cecen K, Cigsar G, Aydin S, Demir A, et al. Association of mean platelet volume and the monocyte/lymphocyte ratio with brucella-caused epididymoorchitis. Southeast Asian J Trop Med Public Health 2016; 47:450-6.

24. Naz H, Korkmaz P, Cevik F, Aykin N. The clinical and laboratory characteristics, treatments, and outcomes of patients with brucella epididymo-orchitis (BEO) compared to those without BEO. Turk J Med Sci 2016; 46:1323-8.

25. Koc Z, Turunc T, Boga C. Gonadal brucellar abscess: Imaging and clinical findings in 3 cases and review of the literature. J Clin Ultrasound 2007; 35:395-400. 